\title{
Intratumoral variations in DNA ploidy and s-phase fraction in human breast cancer
}

\author{
Conny Arnerlöv ${ }^{\mathrm{a}, *}$, Stefan O. Emdin ${ }^{\mathrm{a}}$, \\ Stefan Cajander ${ }^{b}$, Nils-Olof Bengtsson ${ }^{\mathrm{c}}$, \\ Björn Tavelin ${ }^{c}$ and Göran Roos ${ }^{b}$ \\ ${ }^{a}$ Department of General Surgery, Umeå University \\ Hospital, S-901 85 Umeå, Sweden \\ ${ }^{\mathrm{b}}$ Department of Pathology, Umeå University Hospital, \\ S-901 85 Umeå, Sweden \\ c Department of Oncology, Umeå University Hospital, \\ S-901 85 Umeå, Sweden
}

Received 14 November 2000

Accepted 18 May 2001

To study intratumoral DNA ploidy heterogeneity and Sphase fraction (SPF) variability, we prospectively collected five different samples from 48 breast carcinomas and each sample was analysed separately by flow cytometry. Aneuploidy rate was $89.6 \%$ after analysis of four or five samples. DNA ploidy heterogeneity, i.e., different samples classified as either DNA euploid or DNA aneuploid in the same tumor was seen in $17 \%$, and DNA index heterogeneity, i.e., tumor populations with different DNA indices (DIs) seen in different samples was $44 \%$. A statistical model defining SPF heterogeneity is proposed. SPF heterogeneity as defined by us was $71 \%$, and as expected the SPF heterogeneity rate increased significantly with increasing number of analysed samples. Four or more samples are needed to detect the most deviant (highest) SPF values. An unrecognized intratumor heterogeneity of DNA ploidy and SPF may partly explain the conflicting results reported in the literature on the above prognostic indicators.

Keywords: Breast cancer, DNA ploidy, heterogeneity, s-phase fraction, SPF

\section{Introduction}

A large number of studies on DNA ploidy with correlations to tumor stage and different histopathologic, cytometric and prognostic parameters have been per-

\footnotetext{
${ }^{*}$ Corresponding author. Tel.: +46 90785 0000; Fax: +46 90 7851 156; E-mail: Conny.Arnerlov.us@vll.se.
}

formed in human breast cancer. In the majority of these studies only one tumor sample was analysed, and no attention was paid to possible intratumor DNA heterogeneity. The first studies on DNA heterogeneity found it to be rare, but in more recent articles higher rates have been reported, especially when four or more samples have been examined $[4,6,8,12,17,19]$. The prognostic power of DNA ploidy has varied considerably between different studies, a fact which to some extent may be explained by methodological problems and differences in interpretation of the DNA curves, but also to an unrecognized intratumor heterogeneity. Proliferation studies have gained large interest and SPF as determined by flow cytometry are used in clinical protocols to identify risk patients for adjuvant treatment [21]. The variation in SPF values within a tumour and its influence on prognosis has not been sufficiently evaluated. Indeed, no consensus on the definition of SPF heterogeneity has been reached.

In the present study we have analysed intratumor DNA ploidy and SPF variations in breast carcinomas of sufficient size to permit analysis from five different parts. A statistical model for evaluation of SPF heterogeneity is presented.

\section{Material and methods}

\subsection{Patients}

In a prospective study on prognostic indicators in breast cancer, specimens for histopathology, estrogen receptor, progesterone receptor, DNA ploidy and SPF analyses were collected. In 48 patients with primary non-metastatic breast cancer and a tumor size permitting further sampling of tumor tissue, a central slice was cut and divided into five pieces; one central and four quadrant pieces. Thus, five different parts from each tumor were separately analysed for DNA ploidy and SPF. Tumor characteristics are presented in Table 1 . 
Table 1

Tumor characteristics of 48 breast carcinomas

\begin{tabular}{lr}
\hline & $n$ \\
\hline Tumor size $(\mathrm{mm})$ & 1 \\
$0-20$ & 42 \\
$20-50$ & 5 \\
$50-200$ & \\
Histologic grading & 3 \\
highly differentiated ductal carcinoma & 19 \\
intermediately differentiated ductal carcinoma & 25 \\
poorly differentiated ductal carcinoma & \\
Axillary lymph nodes & 16 \\
negative & 27 \\
positive & 5 \\
not examined & \\
Tumor stage & 2 \\
stage I & 41 \\
stage II & 5 \\
stage III & \\
\hline
\end{tabular}

\subsection{Staging and histologic grading}

For stage, the TNM classification of the International Union Against Cancer was used, based on histopathologic data [14]. The original histologic specimens were regraded blindly and all malignant types were graded as well differentiated, intermediately differentiated or poorly differentiated. The grading was based on the percentage of tubule formation, the degree of nuclear pleomorfism and the number of mitoses in a defined field area [10]. The original pathologists' reports were used for data on tumor size and axillary lymph node metastases.

\subsection{Laboratory methods}

Tumor specimens were kept frozen at $-80^{\circ} \mathrm{C}$ until analysis. An imprint was made to assure that adequate malignant tissue was used for analysis. Cell preparation and DNA staining was performed as described by Vindeløv et al. [24]. Chicken and trout red blood cells were used as internal standards. The samples were run in an FACScan flow cytometer (Becton-Dickinson, Sunnyvale, CA, USA). The data were analyzed by the Cellfit software using the RFIT model (BectonDickinson). As a rule 10,000 nuclei were examined. In the histograms the peaks from the trout and chicken red blood cells were reference peaks for calculation of DNA indices (DIs) for the tumor cell peaks. The histograms were classified as euploid when only one sig- nificant G0/G1 peak was found, and as aneuploid when more than one G0/G1 peak was found. The use of reference peaks enabled us to perform a more exact classification of aneuploid samples as hypoploid clones could also be detected. When the G2/M peak was of significant size $(>15 \%)$ and the $1.95<$ DI $<2.05$ the sample was judged as tetraploid. Hypoploid tumors had a defined tumour peak with DI $<1.0$ and multiploid tumors had more than one aneuploid population. In this study we grouped hypoploid, hyperploid and multiploid tumors in the aneuploid group if not stated otherwise. The term tumor heterogeneity has been used with different definitions. In this report we used the term DNA ploidy heterogeneity to define tumors containing both euploid and aneuploid samples. The term DNA index heterogeneity was used to define tumors with different tumor populations in different samples irrespective of the DNA ploidy classification.

SPF was calculated from the FCM histograms by a computer program (RFIT) using the mathematical method described by Baisch et al. [5]. Correction for background was performed. In diploid and homogeneously aneuploid tumors SPF analysis was successful in the majority of samples (85\%). Small aneuploid tumour peaks, multiple peaks, hypoploid peaks (with a SPF impossible to distingish from the SPF from other tumor populations) and background debris made the calculations of SPF unreliable or impossible in $33 \%$ of all specimens. In each tumor, for SPF heterogeneity calculation, the SPF values from the tumor population detected most frequently was used and if more than one population with an equal number of SPF determinations was detected, the SPF values from the population with the highest DI was used.

\subsection{Statistics}

To define the heterogeneity of SPF in analyzed tumor specimens the accuracy of the laboratory analysis for different levels of SPF was determined. In 11 different tumors (not included in this study) with levels of SPF varying between $1.6 \%$ and $23 \%$ five analyses from the same preparation of tumor nuclei were performed by flow cytometry. The relationship between the SPF mean and the SPF standard deviation was found to be linear. The 95th-percentile for the range (maximum SPF - minimum SPF) with 2, 3, 4 or 5 observations from a normal distribution following the observed linear relationship was calculated. The percentiles were estimated using simulation with 10,000 runs at every SPF level between 1 to $40 \%$ (Fig. 1). Definition of SPF 


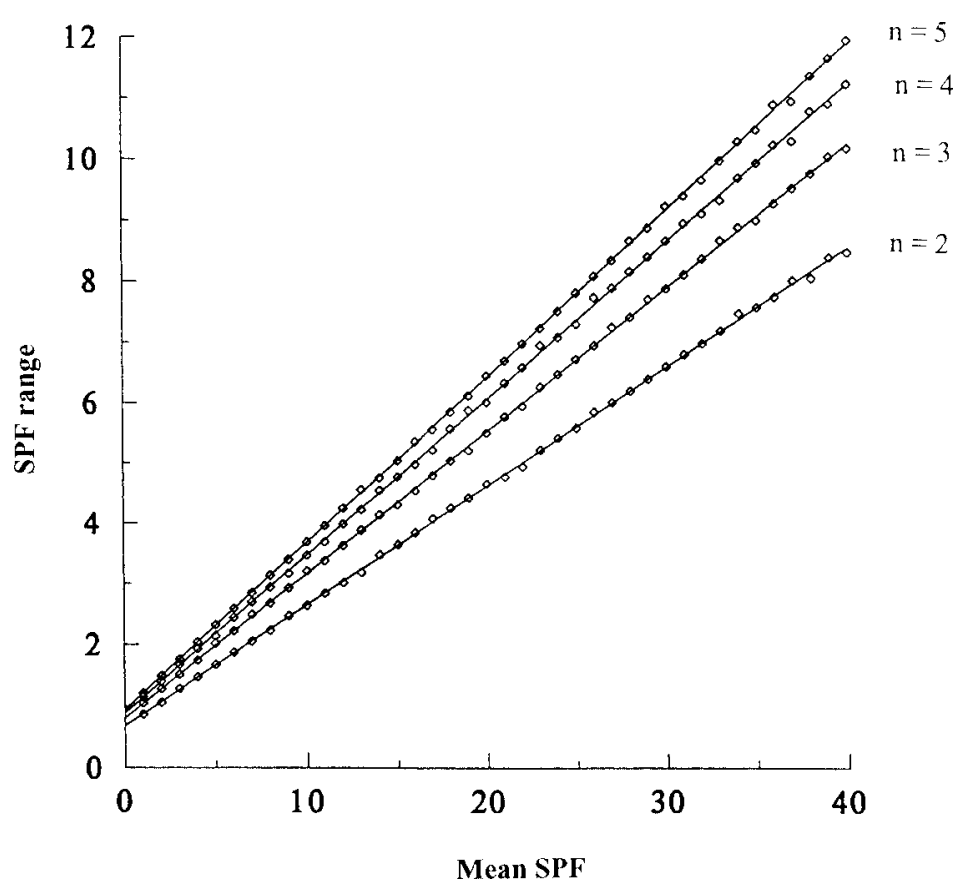

Fig. 1. The statistically calculated 95th percentile curves for linear relationship between the SPF range and mean SPF for each tumor with 2,3 , 4 or 5 observations.

heterogeneity in this study was a SPF range for the different specimens from one tumor exceeding the calculated 95th percentile for SPF range at the mean level of SPF for that specific tumor. The chi-square test was used for contingency tables. A difference was regarded significant if the $p$-value was less than 0.05 .

\section{Results}

Tumor characteristics are presented in Table 1. In 41 tumors five specimens and in seven tumors four specimens were successfully analysed for DNA ploidy. Thus, 97\% (233) of the analysed specimens could be classified as euploid, hypoploid, tetraploid, hyperploid or multiploid. Table 2 shows the DNA ploidy classification of all analysed samples. FCM histograms from one homogenously aneuploid and one multiploid cancer are shown in Fig. 2. Forty tumors were classified as aneuploid (83\%) after analysis of the first specimen, and after analysis of the second specimen aneuploid tumor populations were detected in another three tumors with the resulting aneuploidy rate of $89.6 \%$. Analysis of further specimens did not change the aneuploidy rate. Figure 3 demonstrates the increasing aneuploidy rate after analysis of 1-5 samples. Only in five of the 48 tumors all analysed specimens were euploid (10.4\%).
Hyperploid tumor specimens were found in 25 (52\%), multiploid specimens in 14 (29\%), homogeneuosly hypoploid specimens in two $(4 \%)$ and homogeneously tetraploid specimens in two (4\%) of the 48 breast cancers.

In eight breast cancers the FCM analyses resulted in both euploid and aneuploid FCM histograms in different specimens from the tumor slice resulting in a DNA ploidy heterogeneity rate of $17 \%$. In those eight tumors the classification as DNA euploid or DNA aneuploid after analysis of one sample would depend on which sample that would have been selected for FCM analysis. The DNA ploidy heterogeneity rate increased from $13 \%$ after analysis of two samples to $17 \%$ after analysis of 4-5 samples. Further, in 13 aneuploid tumors $(27 \%)$ the analyses of several samples resulted in the discovery of more than one aneuploid tumor population. Thus, examination of four or five specimens revealed a DNA index heterogeneity rate of $44 \%$ $(8+13 / 48)$. The DNA index heterogeneity rate increased from $29 \%$ to $44 \%$ after analysis of $2-5$ samples. Figure 3 demonstrates the increasing DNA ploidy heterogeneity rate and DNA index heterogeneity rate after analysis of 1-5 samples.

Two hundred seventy-six tumor populations were detected. Adequate SPF determinations were obtained in 186 populations, i.e., $67 \%$, with a mean SPF of 
Table 2

Results of DNA ploidy analysis of all specimens for 48 tumors. $(\mathrm{E}=$ euploid, $\mathrm{Hp}=$ hyperploid, $\mathrm{H}=$ hypoploid, $\mathrm{T}=$ tetraploid, $\mathrm{M}=$ multiploid)

\begin{tabular}{|c|c|c|c|c|c|c|}
\hline Tumour & Specimen 1 & Specimen 2 & Specimen 3 & Specimen 4 & Specimen 5 & $\begin{array}{c}\text { DNA index } \\
\text { heterogeneity }\end{array}$ \\
\hline 1 & $\mathrm{M}$ & $M$ & $\mathrm{Hp}$ & $\mathrm{Hp}$ & & + \\
\hline 2 & M & M & Hp & M & & + \\
\hline 3 & Hp & Hp & Hp & $\mathrm{Hp}$ & Hp & \\
\hline 4 & M & M & M & $\mathrm{Hp}$ & M & + \\
\hline 5 & $\mathrm{E}$ & $\mathrm{E}$ & E & E & E & \\
\hline 6 & $\mathrm{E}$ & $\mathrm{H}$ & E & $\mathrm{E}$ & $\mathrm{E}$ & + \\
\hline 7 & M & M & M & M & & \\
\hline 8 & $\mathrm{Hp}$ & Нp & $\mathrm{Hp}$ & $\mathrm{Hp}$ & $\mathrm{Hp}$ & \\
\hline 9 & $\mathrm{E}$ & $\mathrm{E}$ & $\mathrm{E}$ & E & E & \\
\hline 10 & $\mathrm{Hp}$ & Hp & Hp & $\mathrm{Hp}$ & Hp & \\
\hline 11 & Hp & Hp & Hp & $\mathrm{Hp}$ & Hp & \\
\hline 12 & Hp & Hр & Hp & Hp & Hp & \\
\hline 13 & Hp & Hp & Hp & $\mathrm{Hp}$ & Hp & \\
\hline 14 & $\mathrm{Hp}$ & Hp & $\mathrm{Hp}$ & $\mathrm{Hp}$ & Hp & \\
\hline 15 & E & E & E & E & & \\
\hline 16 & Hp & Hр & Hp & Hp & Hp & \\
\hline 17 & $\mathrm{Hp}$ & Нp & Hp & Hp & & \\
\hline 18 & Hp & Hp & Hp & $\mathrm{Hp}$ & Hp & \\
\hline 19 & $\mathrm{Hp}$ & Нp & $\mathrm{Hp}$ & $\mathrm{Hp}$ & Hp & \\
\hline 20 & M & Hp & Hp & $\mathrm{Hp}$ & Hp & + \\
\hline 21 & $\mathrm{E}$ & $\mathrm{T}$ & E & $\mathrm{T}$ & $\mathrm{T}$ & + \\
\hline 22 & $\mathrm{Hp}$ & Нp & $\mathrm{Hp}$ & $\mathrm{Hp}$ & M & + \\
\hline 23 & Hp & M & M & $\mathrm{Hp}$ & M & + \\
\hline 24 & Hp & Hp & Hp & Hp & Hp & \\
\hline 25 & M & M & M & M & M & \\
\hline 26 & Hp & Hp & $\mathrm{Hp}$ & $\mathrm{E}$ & $\mathrm{Hp}$ & + \\
\hline 27 & $\mathrm{Hp}$ & Hp & $\mathrm{Hp}$ & $\mathrm{Hp}$ & $\mathrm{Hp}$ & \\
\hline 28 & $\mathrm{E}$ & $\mathrm{E}$ & E & E & E & \\
\hline 29 & M & $\mathrm{M}$ & $\mathrm{M}$ & $\mathrm{M}$ & $\mathrm{Hp}$ & + \\
\hline 30 & $\mathrm{Hp}$ & $\mathrm{M}$ & $\mathrm{Hp}$ & $\mathrm{Hp}$ & Hp & + \\
\hline 31 & E & $\mathrm{Hp}$ & $\mathrm{Hp}$ & $\mathrm{Hp}$ & Hp & + \\
\hline 32 & $\mathrm{Hp}$ & $\mathrm{Hp}$ & $\mathrm{Hp}$ & $\mathrm{Hp}$ & Hp & \\
\hline 33 & $\mathrm{Hp}$ & $\mathrm{Hp}$ & $\mathrm{Hp}$ & $\mathrm{Hp}$ & $\mathrm{Hp}$ & \\
\hline 34 & $\mathrm{Hp}$ & $\mathrm{M}$ & $\mathrm{Hp}$ & $\mathrm{T}$ & $\mathrm{T}$ & + \\
\hline 35 & $\mathrm{Hp}$ & $\mathrm{Hp}$ & $\mathrm{Hp}$ & $\mathrm{Hp}$ & $\mathrm{Hp}$ & \\
\hline 36 & $\mathrm{Hp}$ & $\mathrm{Hp}$ & $\mathrm{Hp}$ & $\mathrm{Hp}$ & $\mathrm{Hp}$ & \\
\hline 37 & $\mathrm{H}$ & $\mathrm{Hp}$ & $\mathrm{Hp}$ & $\mathrm{H}$ & $\mathrm{H}$ & + \\
\hline 38 & $\mathrm{Hp}$ & $\mathrm{E}$ & $\mathrm{E}$ & $\mathrm{E}$ & $\mathrm{E}$ & + \\
\hline 39 & $\mathrm{Hp}$ & $\mathrm{E}$ & $\mathrm{Hp}$ & $\mathrm{Hp}$ & Hp & + \\
\hline 40 & $\mathrm{M}$ & $\mathrm{Hp}$ & $\mathrm{Hp}$ & $\mathrm{M}$ & Hp & + \\
\hline 41 & $\mathrm{~T}$ & $\mathrm{~T}$ & E & $\mathrm{T}$ & $\mathrm{T}$ & + \\
\hline 42 & $\mathrm{M}$ & $\mathrm{Hp}$ & $\mathrm{Hp}$ & $\mathrm{Hp}$ & $\mathrm{Hp}$ & + \\
\hline 43 & $\mathrm{Hp}$ & E & $\mathrm{Hp}$ & $\mathrm{Hp}$ & E & + \\
\hline 44 & $\mathrm{Hp}$ & $\mathrm{Hp}$ & $\mathrm{Hp}$ & $\mathrm{Hp}$ & $\mathrm{Hp}$ & \\
\hline 45 & $\mathrm{Hp}$ & $\mathrm{H}$ & $\mathrm{M}$ & $\mathrm{Hp}$ & $\mathrm{H}$ & + \\
\hline 46 & $\mathrm{Hp}$ & $\mathrm{Hp}$ & $\mathrm{Hp}$ & $\mathrm{Hp}$ & $\mathrm{Hp}$ & \\
\hline 47 & $\mathrm{Hp}$ & $\mathrm{Hp}$ & $\mathrm{Hp}$ & $\mathrm{Hp}$ & Hp & \\
\hline 48 & $\mathrm{E}$ & E & E & $\mathrm{E}$ & E & \\
\hline Aneuploidy rate & $83 \%$ & $90 \%$ & $90 \%$ & $90 \%$ & $90 \%$ & \\
\hline \multicolumn{2}{|c|}{ DNA ploidy heterogeneity rate } & $13 \%$ & $15 \%$ & $17 \%$ & $17 \%$ & \\
\hline \multicolumn{2}{|c|}{ DNA index heterogeneity rate } & $29 \%$ & $36 \%$ & $40 \%$ & $44 \%$ & \\
\hline
\end{tabular}


a

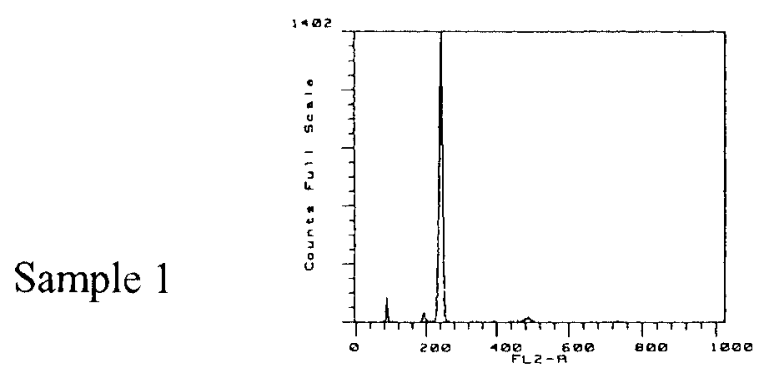

Sample 2

Sample 3
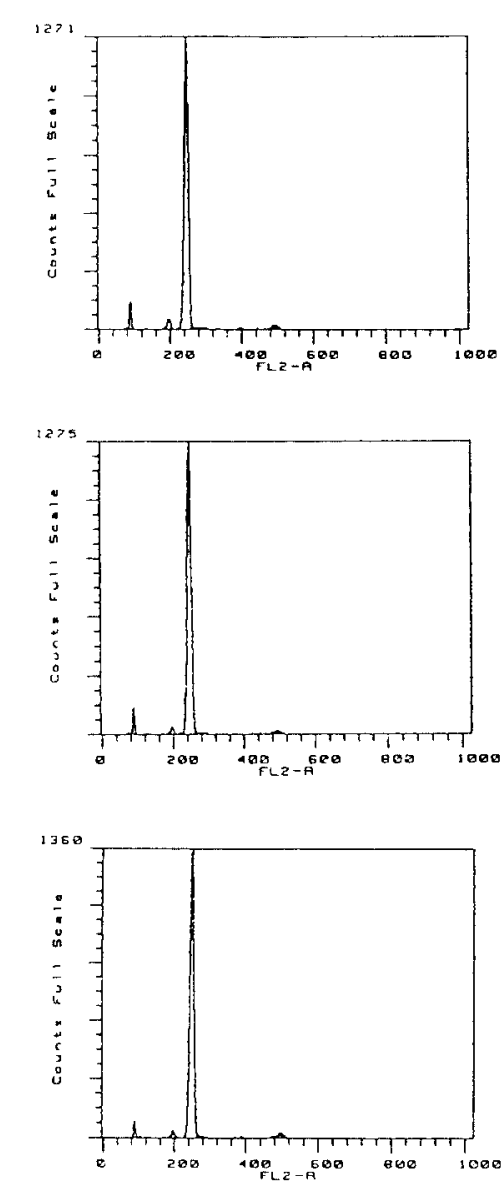

Sample 4

Sample 5

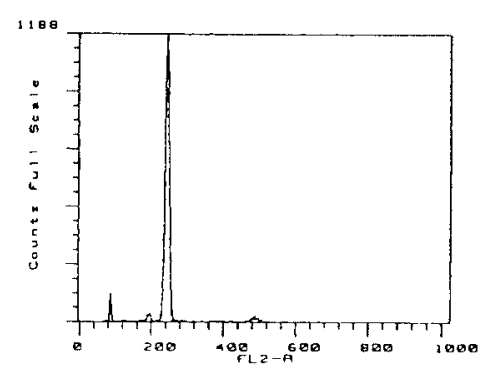

b
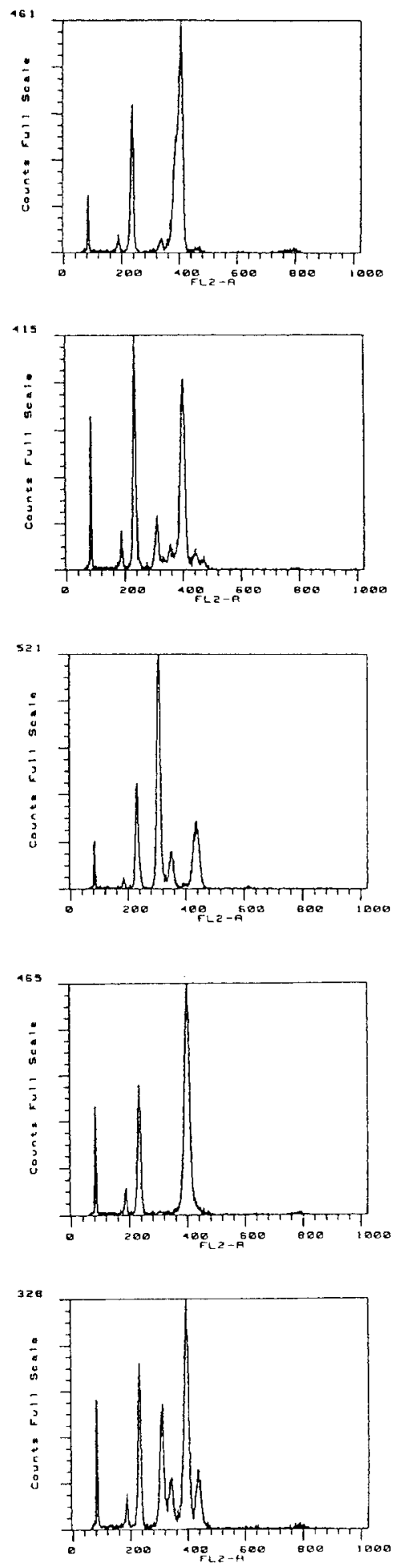

Fig. 2. FCM histograms from one homogenously euploid (a) and one multiploid (b) breast cancer. 


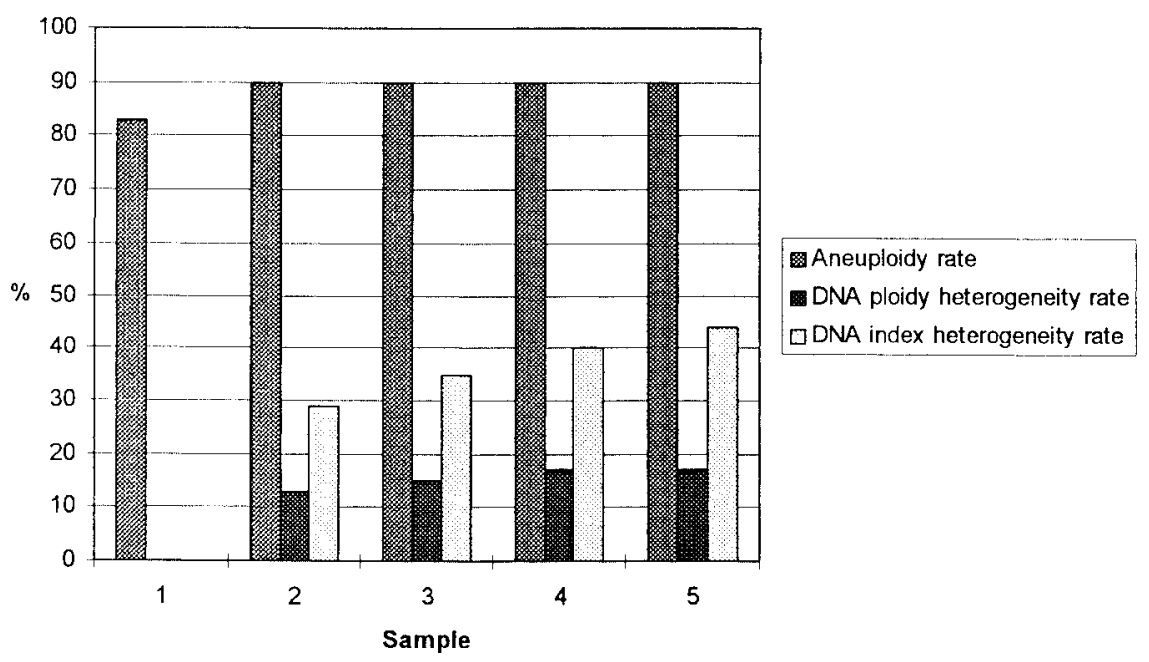

Fig. 3. Cumulative aneuploidy rate, DNA ploidy heterogeneity rate and DNA index heterogeneity rate after analysis of $1-5$ samples.

$9.6 \%$, median of $8.4 \%$ and a range of $0.3-37.1 \%$. Coefficient of variation ranged between 1.1 and $8.8 \%$ with a mean of $3.3 \pm 1.4 \%$. For hypoploid, euploid, tetraploid and hyperploid tumor populations SPF analysis was successful in $55 \%, 76 \%, 64 \%$ and $61 \%$, respectively. Mean SPF values for the different ploidy groups were $11 \%, 5 \%, 6 \%$ and $11 \%$. Adequate SPF determinations for the euploid or most frequent aneuploid tumor population were obtained for 41 of the $48(85 \%)$ analysed tumors. Only SPF values for the same tumor population were compared between samples. Among those 41 tumors SPF analysis was performed in five specimens for 18 , in four specimens for 12 , in three specimens for three and in two specimens for eight tumors. SPF heterogeneity rate as defined by us was $71 \%(29 / 41)$. The SPF heterogeneity rate tended to increase with increasing number of analysed samples; in tumors with two and three analysed specimens the SPF heterogeneity rate was $38 \%$ and $67 \%$ compared to $83 \%$ and $78 \%$ in tumors with four and five analysed samples respectively. The heterogeneity rate was significantly higher when four or five samples were collected compared to only two or three ( $p=0.03$, Chi-square test).

\section{Discussion}

In this report mainly stage II breast cancers were analysed for DNA ploidy and SPF, since these tumors were large enough to permit analyses from five separate pieces. Since aneuploidy rate is largely independent of stage an aneuploidy rate of $89.6 \%$ was surprisingly high. In previous studies using FCM, aneuploidy rates have varied between $60 \%$ and $92 \%$, but mostly between $60-70 \%[1,11,13,18,19,25]$. The high aneuploidy rate could be due to technical improvement of the FCM technique giving histograms of high resolution permitting small aneuploid tumor peaks to be detected. The fact that several specimens were analysed from each tumor also contributed to the detection of more non-euploid tumor peaks. A summary of results from different studies regarding aneuploidy rate, DNA ploidy heterogeneity rate and DNA index heterogeneity rate discovered after FCM analysis of several samples is presented in Table 3. Teixeira et al. in a study of seven carcinomas by cytogenetic analysis found multiple clones in four of the tumors (57\%) and interestingly the clones were unevenly distributed within the tumor mass [22]. The results from the present study with a DNA index heterogeneity of $44 \%$ and a DNA ploidy heterogeneity of $17 \%$ after analysis of 4-5 samples are well in line with previously published results.

It is obvious that analysis of multiple samples from different parts of a tumor increases the detection of non-diploid tumor populations, and thus DNA ploidy heterogeneity rate $[2,3,8,9,12,17]$. FCM seems to be a more sensitive tool than cytophotometry in this respect [2]. In a study of Shackney et al. different solid tumors were examined and the authors showed that $65 \%$ of the tumors had numerical chromosomal abnormalities found by karyotyping, but not detected by FCM [20]. By extensive sampling and different methods to analyse the tumor populations in breast carcinoma tissue several populations and chromosomal abnormalities may be detected. According to Beerman et al. [7] studying breast carcinomas four samples were 
Table 3

Aneuploidy rate, DNA ploidy heterogeneity rate and DNA index heterogeneity rate as reported by different authors

\begin{tabular}{|c|c|c|c|c|c|}
\hline Author & $\begin{array}{c}\text { Tumors } \\
n\end{array}$ & $\begin{array}{c}\text { Samples } \\
n\end{array}$ & $\begin{array}{c}\text { Aneuploidy rate } \\
\%\end{array}$ & $\begin{array}{c}\text { DNA ploidy } \\
\text { heterogeneity rate } \\
\%\end{array}$ & $\begin{array}{c}\text { DNA index } \\
\text { heterogeneity rate } \\
\%\end{array}$ \\
\hline Askensten [2] & 21 & $3-5$ & 67 & 24 & - \\
\hline Bergers [6] & 17 & 6 & - & 53 & - \\
\hline Bonsing [8] & 18 & $1-11$ & 89 & - & 67 \\
\hline \multirow[t]{2}{*}{ Fernö [12] } & 79 & 2 & - & 10 & - \\
\hline & 13 & 4 & 69 & 23 & - \\
\hline Prey [17] & 8 & $5-11$ & 63 & 13 & 25 \\
\hline Schvimer [19] & 28 & 3 & 82 & 14 & 43 \\
\hline Tirindelli Danesi [23] & 102 & not given & 78 & - & 28 \\
\hline Present study & 48 & $4-5$ & 90 & 17 & 44 \\
\hline
\end{tabular}

needed to permit detection of all DNA stemlines with a probability of about $90 \%$, and according to Ljungberg et al. [16] studying renal cell carcinoma at least five samples taken at random were needed to by more than $90 \%$ probability detect an aneuploid or polyploid tumor sample. The prognostic implication of such data have not been sufficiently evaluated. The power of DNA ploidy as a prognostic indicator has been influenced by different techniques for analysis, different methods of classification and also incorrect classification as the aneuploidy rate is underestimated if only one sample is analysed.

In an earlier prospective investigation from our hospital FCM on frozen tumor tissue from breast cancer specimens in an unselected patient material showed the median SPF to be $6.6 \%$ and the mean SPF to be $7.2 \%$ (range $0.3-30.1 \%, n=126$, unpublished data). The higher values in the present study may be explained by our studying cancers of more advanced stages and using multiple samples. The problem with different SPF values in different specimens from of a tumor has been discussed by some authors $[6,12,15]$. There is no agreement on how to define SPF heterogeneity. We have described a statistical model based on the laboratory variation in assessment of SPF values in several samples related to the size of SPF. By our definition of SPF heterogeneity a rate of $71 \%$ was found. Kallioniemi et al. defined a difference of greater than $24 \%( \pm 2$ $\times \mathrm{CV}$ ) between different SPF values as a true intratumor variation and this was found in $36 \%$ of breast cancers after FCM analysis of paraffin-embedded tumors [15]. Bergers et al. found wide ranges for SPF in breast cancers after analysis of up to six samples and especially among aneuploid tumors (0.0-62.7\%), [6]. Fernö et al. divided SPF into three categories (0-7.0\%, $7.0-11.9 \%$ and $12-100 \%$ ) and after analysis of two or four samples $25 \%$ and $45 \%$ respectively showed values in different categories [12]. They also demonstrated that there was a stepwise increase in recurrence rate among patients with increasing SPF category and that patients whose SPF categories varied, from low or intermediate in one part of the tumor to high in another, seemed to have a poor prognosis. Further studies are needed to determine whether the maximal SPF value detected is the one with the greatest prognostic power.

In conclusion, the analysis of several samples from a tumor revealed high DNA aneuploidy, DNA ploidy heterogeneity and DNA index heterogeneity rates. A DNA aneuploidy rate of near $90 \%$ and a high DNA ploidy heterogeneity rate decrease the possible prognostic value of DNA ploidy analysis. SPF values showed large variations between different samples and SPF heterogeneity by our definition was $71 \%$. The influence of the intratumoral variation of SPF on prognostication is not known, but a random sample cannot be expected to give true prognostic information. Multiple sampling seems to be necessary to detect tumor populations with non-euploid DNA pattern and to detect the population with the highest S-phase fraction. According to our study four or more samples are needed to detect the most deviant SPF values. To truely evaluate the prognostic strength of a prognostic predictor, it is essential that it represents the whole tumor and not only a part of it. In future research intratumoral variation must be thoroughly analysed before any prognostic factor is used for clinical decisions.

\section{Acknowledgement}

Financial support: The present study was supported by grants from the Lion's Cancer Research Founda- 
tion, Umeå, Sweden and the Swedish Medical Society, Stockholm, Sweden.

FCM: We thank Mr Kent Persson for excellent technical assistance in performing the analyses.

\section{References}

[1] C. Arnerlöv, S.O. Emdin, G. Roos, T. Ångström, L. Bjersing, K.A. Ängquist and H. Jonsson, Static and flow cytometric DNA analysis compared to histologic prognostic factors in a cohort of Stage T2 breast cancer, Eur. J. Surg. Oncol. 16 (1990), 200 208.

[2] U.G. Askensten, A.K. von Rosen, R.S. Nilsson and G.U. Auer, Intratumoral variations in DNA distribution patterns in mammary adenocarcinomas, Cytometry 10 (1989), 326-333.

[3] M. Aubele and M. Werner, Heterogeneity in breast cancer and the problem of relevance of findings, Anal. Cell. Pathol. 19 (1999), 53-58.

[4] G. Auer, A. Fallenius, K. Erhardt and S.B. Sundelin, Progression of mammary adenocarcinomas as reflected by nuclear DNA content, Cytometry 5 (1984), 420-425.

[5] H. Baisch, W. Göhde and W.A. Linden, Analysis of PCP-data to determine the fraction of cells in the various phases of cell cycle, Radiat. Environ. Biophys. 12 (1975), 31-39.

[6] E. Bergers, P.J. van Diest and J.P. Baak, Tumour heterogeneity of DNA cell cycle variables in breast cancer measured by flow cytometry, J. Clin. Pathol. 49(11) (1996), 931-937.

[7] H. Beerman, V.T.H.B.M. Smit, Ph.M. Kluin, B.A. Bonsing, J. Hermans and C.J. Cornelisse, Flow cytometric analysis of DNA stemline heterogeneity in primary and metastatic breast cancer, Cytometry 12 (1991), 147-154

[8] B.A. Bonsing, H. Beerman, N. Kuipers-Dijkshoorn, G.J. Fleuren and C.J. Cornelisse, High levels of DNA index heterogeneity in advanced breast carcinomas, Cancer 71(2) (1993), 382-391.

[9] P. Devilee and C.J. Cornelisse, Somatic genetic changes in human breast cancer, Biochim. Biophys. Acta 1198(2,3) (1994), 113-130.

[10] C.W. Elston and I.O. Ellis, Pathological prognostic factors in breast cancer. I. The value of histological grade in breast cancer: experience from a large study with long-term follow-up, Histopathology 19 (1991), 403-410.

[11] G.E. Feichter, M. Kaufmann, A. Müller, D. Haag, R. Eckhardt and $\mathrm{K}$. Goerttler, DNA index and cell cycle analysis of primary breast cancer and synchronous axillary lymph node metastases, Breast Cancer Res. Treat. 13 (1989), 17-22.

[12] M. Fernö, B. Baldetorp, S.B. Ewers, I. Idvall, H. Olsson, H. Sigurdsson and D. Killander, One or multiple samplings for flow cytometric DNA analyses in breast cancer-prognostic implications?, Cytometry 13(3) (1992), 241-249.
[13] A. Hitchkock, I.O. Ellis, J.F.R. Robertson, A. Gilmour, J. Bell, C.W. Elston and R. Blamey, An observation of DNA ploidy, histological grade, and immunoreactivity for tumour-related antigens in primary and metastatic breast carcinoma, J. Pathol. 159 (1989), 129-134.

[14] International Union Against Cancer, TNM Classification of Malignant Tumours, 3rd edn, International Union Against Cancer, Geneva, 1982, pp. 47-54.

[15] O.P. Kallioniemi, Comparison of fresh and paraffin-embedded tissue as starting material for DNA flow cytometry and evaluation of intratumor heterogeneity, Cytometry 9 (1988), 164-169.

[16] B. Ljungberg, R. Stenling and G. Roos, DNA content in renal cell carcinoma with reference to tumor heterogeneity, Cancer 156(3) (1985), 503-508

[17] M.U. Prey, J.S. Meyer, K.R. Stone and R.W. McDivitt, Heterogeneity of breast carcinomas determined by flow cytometric analysis, J. Surg. Oncol. 29 (1985), 35-39.

[18] Y. Remvikos, H. Magdelénat and A. Zajdela, DNA flow cytometry applied to fine needle sampling of human breast cancer, Cancer 61 (1988), 1629-1634.

[19] M. Schvimer, R. Lash and W. Katzin, Intratumoral heterogeneity of DNA ploidy in breast carcinomas: a flow cytometric assessment of sampling techniques, Cytometry 22 (1995), 292296

[20] S.E. Shackney, D.R. Burholt, A.A. Pollice, C.A. Smith, R.P. Pugh and R.J. Hartsock, Discrepancies between flow cytometric and cytogenetic studies in the detection of aneuploidy in human solid tumors, Cytometry 11 (1990), 94-104

[21] O. Stål, L. Skoog, L.E. Rutqvist, J.M. Carstensen, S. Wingren, S. Sullivan, A.C. Andersson, M. Dufmats and B. Nordenskjöld, S-phase fraction and survival benefit from adjuvant chemotherapy or radiotherapy of breast cancer, $\mathrm{Br}$. J. Cancer 70(6) (1994), 1258-1262.

[22] M.R. Teixeira, N. Pandis, G. Bardi, J.A. Andersen and S. Heim, Karyotypic comparisons of multiple tumorous and macroscopically normal surrounding tissue samples from patients with breast cancer, Cancer Research 56 (1996), 855-859.

[23] D. Tirindelli Danesi, M. Spanò, F. Antonini, P. Altavista, P. Catalano, E. Cordelli, P. Pasqualetti, C. Santacroce, M.G. Toscano, A. Mecozzi and A. Fabiano, Flow cytometric and immunohistochemical correlations in high incidence human solid tumors, Tumori 83 (1997), 689-697.

[24] L.L. Vindeløv, I.J. Christensen and N.I. Nissen, A detergenttrypsin method for the preparation of nuclei for flow cytometric DNA analysis, Cytometry 3 (1983), 323-327.

[25] D.J. Winchester, R.B. Duda, C.Z. August, R.A. Goldschmidt, D.M. Wruck, A.W. Rademaker, D.P. Winchester and D.E. Merkel, The importance of DNA flow cytometry in nodenegative breast cancer, Arch. Surg. 125 (1990), 886-889. 


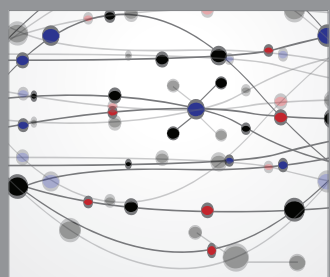

The Scientific World Journal
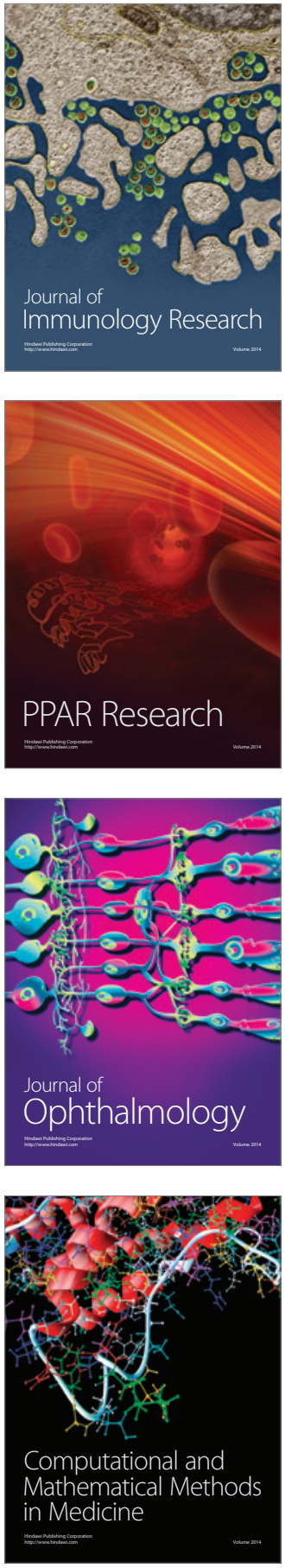

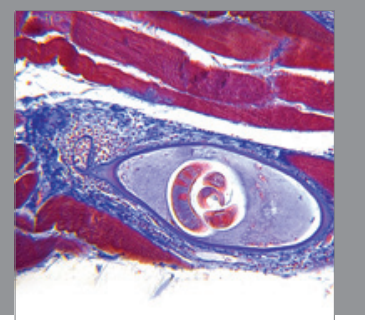

Gastroenterology

Research and Practice
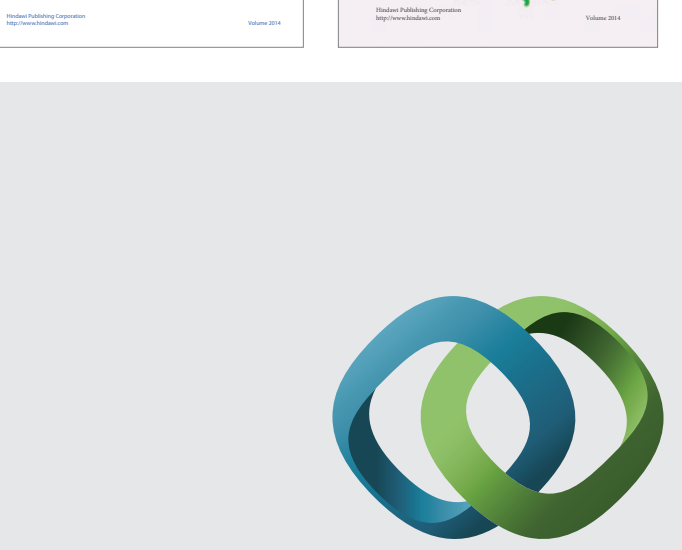

\section{Hindawi}

Submit your manuscripts at

http://www.hindawi.com
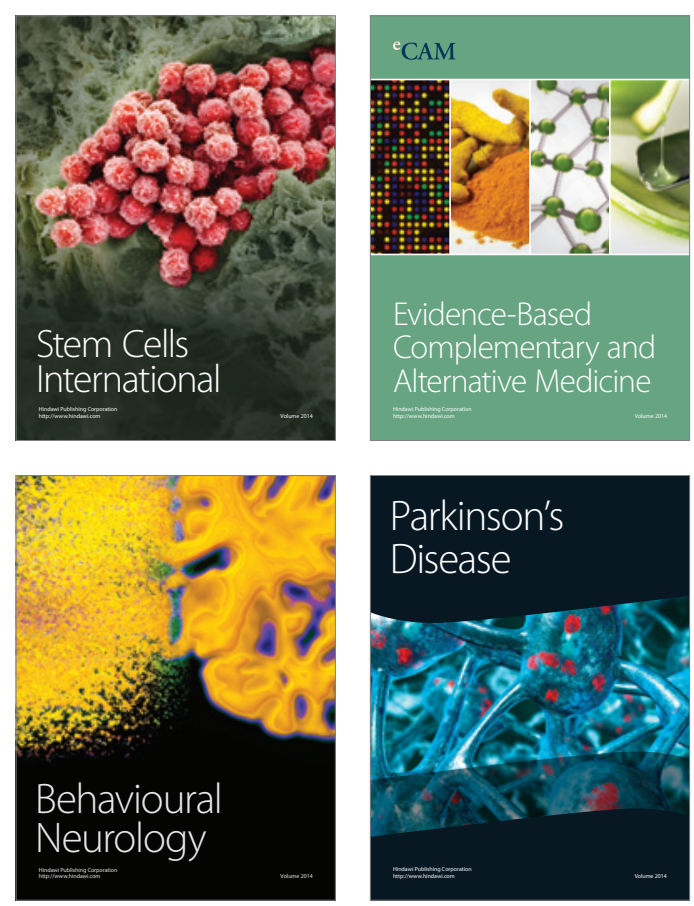

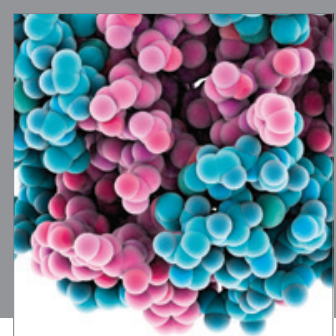

Journal of
Diabetes Research

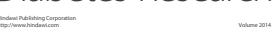

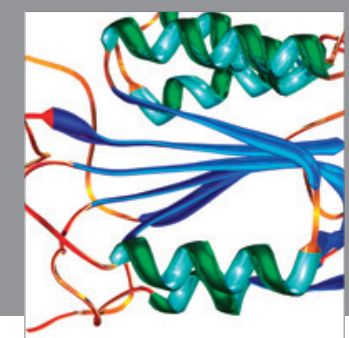

Disease Markers
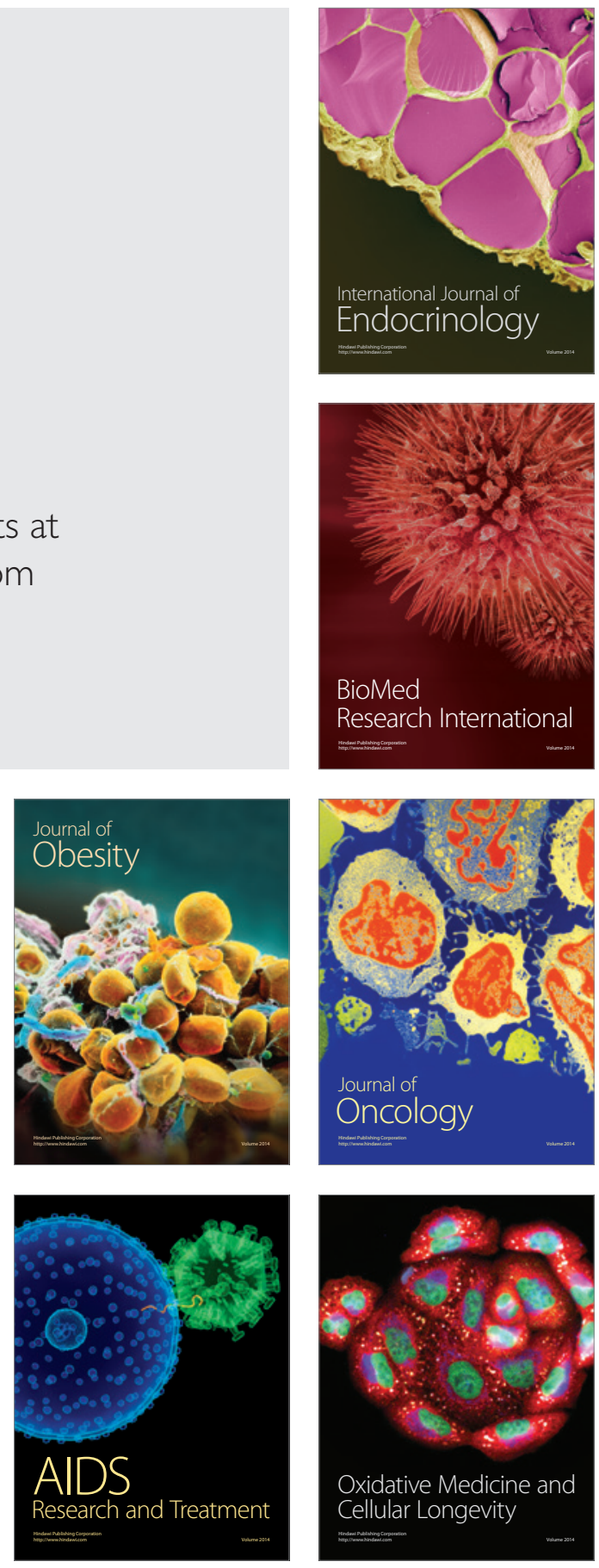